\title{
Implementing Project-Based Experiential Learning in Post-Graduate Studies in Greece: A Case Study
}

\author{
Karageorgou Elissavet, PhD Cand. \\ Koutrouba Konstantina, Assoc. Prof. \\ Harokopion University, Athens, Greece
}

\begin{abstract}
The present questionnaire-based study examines the outcomes of project-based learning procedures in Greek University postgraduate classes, where the project entitled "Traffic Signs" takes place. Master in Education students at Harokopio University provided relevant information by answering a set of close-ended questions specifically designed for the research. Data elaboration and statistical analysis were performed. The results of the study showed that, according to MEd students, the teachers' role during the carrying-out of the project remains crucial, since s/he establishes the rules of communication, defines the objectives, simplifies the learning material and intervenes in a supportive way to strengthen students' cognitive background and self-confidence, to overcome setbacks and facilitate constructive cooperation. The research also showed that as long as projects' implementation during postgraduate studies are well-designed, attractive and demanding regarding high-ranked cognitive and socio-affective abilities, they meet satisfactorily students' academic needs and expectations and refresh, deepen and expand the positive outcomes of the learning procedure even in scientific domains where very often University teachers tend to avoid the use of more innovative teaching methods.
\end{abstract}

Keywords: project-based learning, post-graduate studies, 'Traffic Signs', Greece

\section{Introduction}

It is commonly accepted that the majority of higher education institutions' curricula at both undergraduate and postgraduate level are often criticized in recent years. The majority of them are based on teaching methods which intend only to transmit information to students, turning them into passive receivers. They are mainly overloaded mainly with theoretical content, which often students fail to digest and put into practice (Karageorgou, 2011). New and innovative teaching methods are proposed in order to promote consistency between theory and practice. One of these is learning-based Research Project (Project Based Learning, PBL), which is a popular and powerful teaching tool, suitable for teaching into several practical courses (Janeck \& Bleek, 2002). It can be applied at both undergraduate and postgraduate courses, as it is clearly focused to students as units (Barrows \& Tamblyn, 1980).

\section{Literature Review}

Literature defines the trainers' role in work plans and a university teacher is a trainer and a facilitator during the project. An academic teacher-student relationship has to be collaborative, such as the relationship between colleagues. It is important to trust all students in achieving the objectives of the course, as they can suggest possible sources of information after examining their suitability. Through PBL projects, students deal with issues-problems of the real world, so all necessary knowledge is built on the subject and talents and skills can cultivate through group cooperation. As in all work plans, students lead themselves to the development of the final project, constitute the final outcome of the design work and eventually assimilate to actual working conditions (Vlamos, 2013).

Students are "free" to determine their own objectives of how to analyze the problem, seek relevant and useful information to efficiently manage the available time at their disposal for the completion of the project, to design, develop and monitor the progress of each option plan to complete the work (Kilroy, 2011). 
Project is the main alternative educational strategy for adults, along with case study and role-play (Blumenfeld, 1991). It is considered to be highly appropriate due to the fact that learners take initiatives; it involves discovery learning, group work, individualized instruction, extension of work beyond one lesson, final presentation and the reversal of teacher roles, from instructor to coordinator and a facilitator of the process. Project is based on two very important principles: that of social interaction and collaboration and that of interdisciplinarity. It highly contributes to students' assessment because trainers have to evaluate participation and willingness of trainees to promote their work (Karageorgou, 2011).

Indicative areas of Project Based Learning courses' implementation are- besides Education -the Research Methodology, Technology, Economy \& Innovation and Modeling. Examples Interim Project- based Courses are marginalization of gifted students, use Webcast in the educational process, improving activities of extracurricular activities, the historical development of nationalism, map pollutants in urban areas, improving turbine efficiency, stem cell modeling, seismic identity of buildings etc (Vlamos, 2013).

Project implementation has several results in students such us cultivation of transferable skills, which can be applied to areas other than those acquired and include communication skills, ability to work in a team, critical thinking and selfassessment and link between theory and practice (Karageorgou \& Koutrouba, 2014). Students discuss various alternatives during their meetings, argue and develop tolerance of ambiguities, appreciate the knowledge from various sources, develop analytical thinking skills and cultivate self-directed learning skills (Barrows \& Tamblyn, 1980).

\section{Stages of Implementation of Action Plans in Higher Education and Steps Followed}

The steps in preparing a work plan at undergraduate and postgraduate level follow the same rules as steps of each project. Initially, students set the scope management (scope of the work), the mission statement (general purpose) and the goals of the project (specific objectives) of each work, they create working groups, define the project manager (leader of each group) and the time management (schedule of work). Each team determines the activities required for the development of their work and makes division operations; in that way, they are able to find the optimal path (critical path) of work. A necessary condition for the proper course and group operation is the quality management (quality management) and communication management (communication management) (Vlamos, 2013). Important is the role of the leader in each group, and the flexibility of the leader to enrole with students, so that possible discrepancies that had been received from the predetermined schedule, to change (Karageorgou \& Stefou, 2014). Additionally, the team coordinator is the link for communication between students and academic teachers-mentors and finally has the role to present the work results in people who may vary from classmates to academics (Blumenfeld, 1991).

The steps of the educational process are essentially the same as defined above, ie initial clarification of terms and concepts which have not been understood, following the definition of the problem and the analysis that leads to the formulation of ideas and assumptions, gather all explanations and formulate the objectives of learning, add more information, synthesis and testing of new knowledge gained. The problem chosen to 'trigger' learning usually arises from the objectives of the specific session ((Spector et al, 2008). It must be based on actual data, reflect accurately the situations facing the students in the workplace and it is prudent to have an appropriate level of complexity, in order to motivate students and to provoke interest in learning and not find it simplistic or boring, but at the same time not be too complex in order not to discourage. The theme of the project needs special care, no limitation to reference and theoretical knowledge-important to fit into the semester in which students are and their level of knowledge - cognitive maturation (Vlamos, 2013).

The project methodology splits in skeptical and empirical basis, ie the theoretical substance of the matter and the practical reality. Students should keep in mind that the more empirical data they collect, the more strengthened their theory is and easier the next steps will be to make description, correlation, prediction and causality through variable control Schmidt et al, 2006). The project objective is to find reliable solutions to practical problems through systematic and planned collection, analysis and interpretation of data, especially when the research is applied, that is performed in order to acquire new knowledge, but directed primarily towards a specific practical aim or objective and finally transform ideas into functional form. Such a project may contribute to technological development is being held with systematic work which draws from the knowledge gained from research and practical experience, and is directed to produce new materials, products or devices, to installing new processes, systems and services, or to improving substantially those already produced or installed (Spector et al, 2008). 
The purpose of this research is to investigate both the theoretical and research role of academic teachers as leaders' during project management, according to the perceptions of learners. The survey is carried out on postgraduate students due to the fact that there is no extensive research on the use of alternative teaching methods in postgraduate studies.

\section{Traffic Signs}

The project that was carried out involved Mathematics, Home Economics, IT, Physics, Greek Language, Social and Political Education and Art lessons. It was applied as an example of alternative teaching technique due to the fact that it is short in duration (three-hour implementation) and mixes basic geometrical terms such as 2-dimension shapes, symmetry rules and traffic education coming out of the lesson of Home Economics, the basic lesson that undergraduate alumni from the Department of "Home Economics and Ecology" in Harokopion Univercity are allowed to teach in Gymnasiums and of the lesson Social and political Education. Those were the basic lessons involved which had a lot of cognitive subjects to be learned. In Mathematics-Geometry in particular- all cognitive goals to be achieved were clearly set and into the curricula, in Home Economics and Social and Political Education however, the cognitive goals were not so strictly specified by curricula and they included personal opinions from driving/walking into the streets, driving abilities and personal experience in driving behavior. The rest lessons came in to fill-in equally the cognitive side of the project, so all these lessons could conclude to the final result successfully. Before project began, all students were informed about projects' theme. They were also informed that it would be helpful to bring with them all project theory, so in every step they could be in trainers' "shoes", so at the beginning, the first step was omitted. All students were split to teams of 5 persons each. At that point, all implementation tools ie cartons, post-it papers, glue, straws, colorful markers, scissors, and pieces of A4 paper were put on desk. They had also all IT technology at their allowance ie laptops, wifi access, projectors etc. The class was enthusiastic as they were face to face with something not familiar to them (Pic1,6). Although Mathematics tends to scare them, the fact that they had all their notes with them, by teachers' guidance, they felt better on the way. After that stage, they were free to cut in circle or in any other shape all traffic signs they remembered and draw them with the markers (Pic4, 5), so they were able to "play" and feel children again, and discover their talent in creativity. (Pic3). The final product which included also a pp presentation was completed and presented to other students (Pic2) and the MEd Director as well.

\section{Methodology}

In order to conduct this research, as it was described above , the "Traffic Signs" project was completed by 50 students of a two-year postgraduate program "Education and Culture" in Harokopio University -and specifically students that attended the division "Educational Psychology and teaching practice". The present research was conducted during the academic year 2014-15. The methodological approach that was used was the observation by the author, all photographic archive that was taken during the implementation and a questionnaire completion of a sample of the 50 students that attended (response rate of $100 \%$ ). All results of descriptive statistics among the variables are presented and a comment analysis of key results has been made, with some additional proposals.

\section{Analysis of Results}

\section{A. Participants' profile}

The male postgraduate students' percentage (54\%) was higher than that of females (46\%). It is worth mentioning that most of the respondents belong to the age group (21-30) and were single with none previous experience in project implementation.

\section{B. Special questions}

Postgraduate students report (Table 1) that their leader was very often/always aware of all project procedures (78\%). $66 \%$ of the respondents state that $\mathrm{s} / \mathrm{he}$ always made clear from the beginning all basic steps and stages to be followed and most of them (84\%) also mark that they chose their coordinator by themselves and act freely when they are separated in teams, statement by almost all of the sample $(94 \%)$. The project leader-at a very high percentage (88\%)-does not control but coordinates and guides the process and constantly gives feedback to all team members whenever it is necessary $(80 \%)$.

According to the data, the majority (94\%) very often/always uses photos, slides, comics, graphics etc during their implementation. However, just half of them (52\%) enjoy the process of collecting data. Furthermore, the research revealed 
that most of the respondents $(78 \%)$ reported that their previous knowledge is very often/always recovered through project implementation. The same sample $(78 \%)$ also stated that through project implementation they manage to mix harmonically knowleghe with society, technology and environment. In addition to that, $89 \%$ of them managed to gain personal involvement in all learning activities. However, approximately a bit more than half of them (62\%) stated that they become familiarized with information technologies, although $84 \%$ reported that they managed a successful usage of all cognitive lessons included in their project. More than half of them (64\%) also reported that they can very often be objectively evaluated by their trainer. All communicative skills seemed very often/always $(96 \%)$ to have been grown and $80 \%$ of students said that familiarizing themselves with different ideas is useful but they rarely/often do want to lead the team, as $48 \%$ stated. In conclusion, project implementation seems very often/always to help students strengthen their pedagogical background as $80 \%$ of them reported, grow their communicative skills $(88 \%)$ and bring to practice all theoretical framework that has been taught (94\%). In that way, project seems to achieve its basic goal which is guidance to proper thought construction, according to $86 \%$ of the participants in the survey.

\section{Discussion}

Through observation and all data analysis, literature seems to be confirmed as far as project being strongly a useful tool to academic teachers. By addressing the above technique to graduate students they seem to learn how to learn (Karageorgou \& Koutrouba, 2011) and acquire skills that will lead them to discover knowledge (Karageorgou \& Koutrouba, 2014). Dewey is also confirmed, since project method knowledge is transferred through interactive processes to students by their peers, their teachers and the environment in which all the above coexist, while traditional teaching knowledge is transferred through books to students only by their teachers. Regarding to the subject of mathematics, teaching mathematics is undoubtedly a complex activity. It has two sides, first to teach students how to connect the observation of reality with representations such as images, shapes, tables and also to teach students to connect these representations with some mathematical activity and concepts (Chevalier, 2000). Projects lead students to understand better the instrumental nature of mathematics.

Through implementation, teachers' involvement in working plans takes a complex role. S/he coordinates every step of the trainees during their atomic work and their overall work within groups (Biggs, 1999). S/he necessary has to encourage the efforts of all learners especially those who have difficulty or are marginalized by lack of knowledge, skill or courage. Project promotes a variety of ways to be self-motivated and cooperative, it provides opportunities for initiative so that each learner becomes competent, productive and efficient and creates and maintains a democratic and participatory climate. Teacher acts as moderator, as a partner, providing all possible assistance without prejudging the decisions and actions of learners. The key to successful implementation is an active participation of students in each step of the process. To successfully implement the group work, an academic teacher is required to have no tendency to anticipate and coordinate everything, need to have no eagerness for faster moves, trust the capabilities of all learners and allow them to take initiatives and have the skills to meet the requirements for the effective functioning of groups (Blumenfeld, 1991).

\section{Proposals}

All adult trainers, including academic teachers, in order to make their class attendance more attractive, need to attend continuous training programs to update cognitive backgrounds and skills against the traditional methods of teaching. The academic teacher must be a professional (Karageorgou, 2014). Of course, an important element for all this to be efficient is the existence of material and technical facilities. In Greece, the professionalism of adult educators is still developing. The continuous combination with teaching, alternative teaching methods, knowledge of each subject and motivation are important factors for the development of professional competencies of adult educators (Karageorgou \& Koutrouba, 2013). Given the fact that laboratory personnel comes from formal education - and therefore tends to carry every stereotyped and conventional teaching trends in university classes, the need of the training support for teachers, young and old gets bigger.

Undergraduate and postgraduate teachers should be encouraged by their Administration to join/participate in pedagogical nature facilities and incentives in conferences so they are informed for all alternative forms of education and integrate them into teaching. Finally, pedagogical courses should be held, with emphasis in the field of alternative teaching as it is now undeniable that they contribute to a better school performance for learners and especially adults. 


\section{References}

[1] Barrows H, \& Tamblyn R., (1980), Problem-based learning: an approach to medical education. New York: Springer

[2] Biggs, J., (1999), Teaching for quality learning at university: what the student does Higher education, 40 (3), 374-376

[3] Blumenfeld, K., (1991), Managing the Product Life Cycle, Management Review, 80

[4] Chevalier, M., (2000), Alternative teaching Methods in Mathematics, in: Issues of Math Didactics V: Interdisciplinary Approach of Mathematics and its Teaching, University of Aegean: Gutenberg, p225-240

[5] Janeck, M. \& Bleek, W.G., (2002), Project-Based Learning with CommSy, in: Conference on Computer-Supported Collaborative Learning (CSCL 2002), USA: University of Colorado, Boulder, CO

[6] Karageorgou, E., (2011), Project implementation as a teaching method and as a measure of cognitive and psychological outcomes of Greeces Second Chance Schools, from the perspective of learners, Dessertation, Athens: Harokopio Univercity [in Greek]

[7] Karageorgou, E., (2014), Project Implementation in Didactics of Maths, Dessertation, Patrai: Hellenic Open University [in Greek]

[8] Karageorgou, E. \& Koutrouba, K., (2011), The views of Second Chance Schools' students about the role of their educators during project method procedures: The case of Greece, in: International conference on Excellence in Education, ICIE 2011, Turkey: Istanbul

[9] Karageorgou, E. \& Koutrouba, K., (2014), Project management in Education-the case of Greece: Project implementation in Second Chance Schools in: International Conference on Advances in Management, Economics and Social Science MES 2014, Italy: Rome

[10] Karageorgou, E. \& Stefou, T., (2014), The teacher as a leader in educational project management in Second Chance Schools. Perceptions of Greek Adult Students, in: International Conference on Advances in Management, Economics and Social Science MES 2014, Italy: Rome

[11] Kilroy, D., (2011), Problem based learning, Emerg Med J, 21:411-413

[12] Koutrouba, K. \& Karageorgou, E., (2013), Cognitive and socio-affective outcomes of project-based learning: Perceptions of Greek Second Chance School students, Improving Schools, 16(3), 244-260

[13] Schmidt, H.G., Vermeulen, L. \& Van der Molen, H.T., (2006), Long-term effects of problem-based learning: a comparison of competencies acquired by graduates of a problem-based and a conventional medical school, Med. Education, 40(6), 562-567

[14] Spector, M., Merrill, D., Merrienboer, J.V. \& Driscoll, M., (2008), Handbook of Research on Educational Communications and Technology, 3rd Ed, NY: Taylor and Francis

[15] Vlamos, $P_{, ;}$(2013), Project based Semester Lessons (Seminar 'Methodology and Applyance of Projects in Education'), Athens: Harokopio University

Table 1

\begin{tabular}{|l|l|l|l|l|}
\hline $\begin{array}{l}\text { Degree of acceptance of the following sentences by the students, } \\
\text { through project implementation (\%) }\end{array}$ & Often & Very often & Always \\
\hline A1 & Recovery of previus knowleghe & 30.0 & 50 & 28 \\
\hline A2 & Mix of knowleghe with society, technology and enviroment & 10.0 & 50.0 & 28 \\
\hline A3 & Familiarize with IT & 24 & 42 & 20 \\
\hline A4 & Objective assessment by trainer & 32 & 58 & 6 \\
\hline A5 & Personal involvment in learning activities & 12 & 34 & 55 \\
\hline B1 & Development of communicative skills & 2 & 52 & 44 \\
\hline B2 & Familiarization with different ideas & 20 & 38 & 42 \\
\hline B3 & Leading ambitions & 48 & 18 & 10 \\
\hline B4 & Preferance to timeline & 20 & 36 & 30 \\
\hline
\end{tabular}




\begin{tabular}{|l|l|l|l|l|}
\hline C1 & Knowleghe of steps/planning from the beginning & 16 & 28 & 50 \\
\hline C2 & Coordinator chosen by team & 14 & 38 & 46 \\
\hline C3 & Foster self-motivation and initiatives & 26 & 36 & 24 \\
\hline C4 & Collection of data & 24 & 36 & 16 \\
\hline C5 & Use of photos,slides etc & 4 & 56 & 38 \\
\hline C6 & Use of all cognitive lessons & 14 & 32 & 52 \\
\hline D1 & Guides to proper thought construction & 12 & 44 & 42 \\
\hline D2 & Free choice of team members without leading intervation & 6 & 28 & 66 \\
\hline D3 & Coordinates and does not control & 12 & 22 & 66 \\
\hline D4 & Constant feedback to team members & 14 & 14 & 66 \\
\hline E1 & Stregthen of paidagogical backround & 18 & 54 & 26 \\
\hline E2 & Grow communicative skills & & & \\
\hline E3 & Cooperation with trainer & 10 & 46 & 42 \\
\hline E4 & Practise all theoritical framework & 14 & 38 & 44 \\
\hline
\end{tabular}

\section{FIGURES-PICTURES}

Picture1

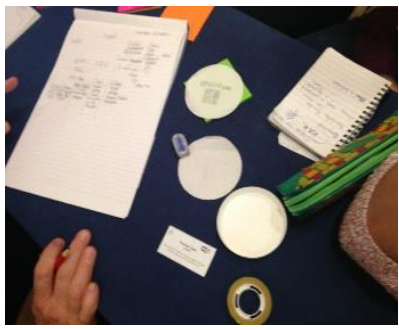

Picture4

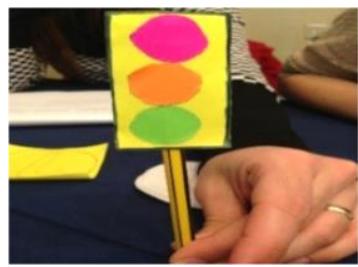

Picture2

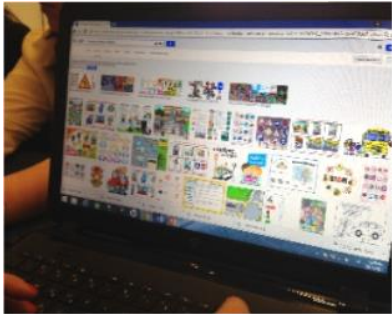

Picture5

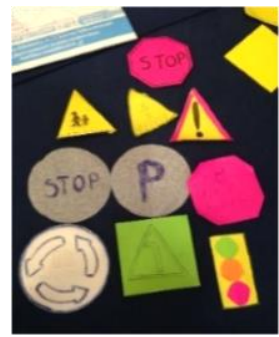

Picture3

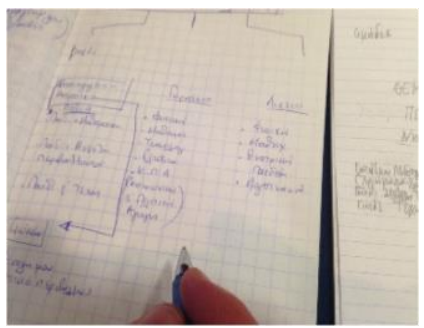

Picture6

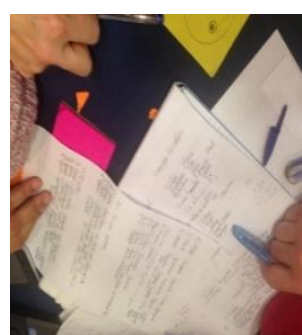

